\title{
EDUCATION
}

\section{An Evidence-Supported Medical Laboratory Science Program Admissions Selection Process}

\section{JANICE M. CONWAY-KLAASSEN}

\begin{abstract}
After a recent enrollment expansion, a Medical Laboratory Science program experienced a higher than desired student attrition rate due to a number of academic and non-academic student readiness factors. In an attempt to address retention and other issues, the program completed a curriculum update and revision as well as a conversion to a hybrid or flipped classroom delivery model, but in spite of an overall improvement in student learning outcomes, the program still experienced a high level of student attrition. Program faculty then developed and implemented a two stage holistic admissions selection process, which included an interview and skills test, in an attempt to assess candidate background knowledge and abilities in an equitable manner. Comparison of student factors associated with on-time successful graduation, probation (delayed graduation), or dismissal from the program indicated that the science and prerequisite science grade point averages were significantly higher for students who graduated on-time compared to delayed or nonsuccessful (dismissed) students. Review of applicants' performance in the interview and skills test showed significant differences for multiple factors for students who graduated on-time from the program compared to delayed (probation) and non-successful (dismissed) students. Continuing reviews of program retention rates are needed, however the attrition rate for the next cohort dropped from $24 \%$ to $4 \%$ when the program focused the selection process on factors shown to be associated with successful graduation.
\end{abstract}

ABBREVIATIONS: MCAT - Medical College Admission Test, ACT - American College Test, SAT Scholastic Aptitude Test, GPA - Grade Point Average, AHPAT - Allied Health Professions Admission Test, MLS - Medical Laboratory Sciences, ANOVA - Analysis of variance, sGPA - Science GPA, preGPA - Prerequisite science course GPA, TOEFL - Test of English as a Foreign Language, PPB - Purdue Pegboard
INDEX TERMS: Medical Laboratory Sciences, allied health, health education, admissions

Clin Lab Sci 2016;29(4):227-236

Janice M. Conway-Klaassen, PhD, MT(ASCP)SM, FACSc, Medical Laboratory Sciences Program, University of Minnesota, Minneapolis, $M N$

Address for Correspondence: Janice $M$. ConwayKlaassen, PhD, MT(ASCP)SM, FACSc, Program Director, Medical Laboratory Sciences Program, University of Minnesota, 420 Delaware Street SE, MMC 711, Minneapolis, MN 55455, 612-626-9408, jconwayk@umn.edu

\section{BACKGROUND}

The primary purpose of an admission selection process for health-related programs is to predict which candidates will be successful in their academic programs as well as hopefully in their chosen careers. Most of these programs require a standard set of prerequisite science courses such as general and organic chemistry, math, biology, statistics, physics, and anatomy/physiology. Students typically also have to complete a number of non-science or general education courses prior to admission, e.g. English and psychology. ${ }^{1}$ Post-baccalaureate medical programs may also require students to take standardized admissions tests such as the Medical College Admissions Test (MCAT). ${ }^{2}$ In addition to quantitative or cognitive factors, admissions committees must also be able to evaluate qualitative or noncognitive traits of candidates associated with successful completion of the academic program. In spite of best efforts, most programs still admit a few students who struggle; requiring students to repeat courses or years and resulting in some students being dismissed from the programs. Student attrition negatively impacts faculty and other students in the programs as well as universities or colleges overall. 


\section{EDUCATION}

High attrition rates could also negatively impact professional program accreditation. The financial impact for unsuccessful students is also of great concern.

Studies investigating health program admission processes have shown positive correlations between successful student outcomes (on-time graduation) and cumulative, science, and prerequisite grade point average (GPA), performance in prerequisite courses and formal program courses, as well as performance on preadmission standardized tests. Studies looking at dental hygiene graduates' performance on the national board exams showed a strong correlation with scores on the reading comprehension portion of the American College Test (ACT) and grades in the general microbiology prerequisite course. ${ }^{3-5}$ Similarly, a meta-analysis of nursing school outcomes found that Scholastic Aptitude Test (SAT) and ACT scores as well as pre-nursing GPA were predictors of student success in the program and on the nursing board exams. ${ }^{6}$ Another study showed a positive correlation with the Allied Health Professions Admission Test (AHPAT) and successful completion of a baccalaureate laboratory science program. ${ }^{7}$ A metaanalysis of medical school graduates showed similar results with the MCAT exam and prerequisite GPA. ${ }^{8}$ In addition to grades and standardized test scores, programs may also include letters of reference, personal statements, and interviews in the admissions selection process however, these have shown mixed efficacy for predicting student success. ${ }^{6,9}$ A review of admissions processes, with an emphasis on programs in radiologic technology, found that these programs use similar GPA and standardized testing results, along with multiple noncognitive factors such as interpersonal skills, communication, motivation, and work ethic, along with problem solving. ${ }^{10}$

\section{INTRODUCTION}

The Bureau of Labor Statistics predicts a $16 \%$ growth rate for laboratory workforce personnel between 2014 and 2024, which is much faster than average. ${ }^{11}$ Multiple factors are driving these expanding demands for laboratory personnel. ${ }^{12-14}$ As the "baby boomer" population ages, there is an expectation of increased utilization of laboratory testing along with other medical support services. Baby boomer personnel currently in the workforce will be retiring soon, taking with them a mature workforce and long-term expertise. Added workforce pressure comes from an ever increasing array of medical laboratory tests and the consumer demand for direct access to care. Finally, the implementation of the Affordable Care Act has increased the number of individuals now covered by medical insurance which is in turn predicted to cause an increase in testing utilization across the country.

An assessment of our state's current allied health workforce numbers, distribution, and demographics initiated a push to provide more healthcare personnel throughout the state, particularly in rural areas. In July 2006, the University's Board of Regents established the Center for Allied Health Programs as an academic structure to focus on allied health programs and to address the state's projected statewide shortages of allied health professionals. The Medical Laboratory Sciences (MLS) Program was one of the programs moved into the Center from the Medical School. Along with the change in administrative structure, the MLS program was charged to expand offerings to coordinate campus locations within the University system and develop academic affiliations with state college system schools to subsequently expand enrollment from 30 to at least 60 students per cohort year.

In previous admissions procedures, students from majors across the university were accepted into the program on a rolling, first-come/first-admitted basis as long as they had successfully completed the prerequisite courses and met the minimum GPA requirement of 2.50 . In addition, an informal interview process took place during pre-application advising to assess students' readiness for the program. This process had been in place for at least the past 10 years and seemed to be adequate for the program's needs at that time. However, several challenges were encountered when, in an effort to increase annual enrollment, the program expanded the recruiting network inside and outside of the university.

Although graduation metrics met the minimum accreditation requirements, the program experienced a higher than desired attrition rate; almost $24 \%$ of admitted students were delayed or were not able to graduate at all due to academic or personal struggles. 


\section{EDUCATION}

Many students did not seem prepared for the rigor of the program nor were they prepared for the intense workload of the full-time enrollment model especially for students who came from outside the University. Although students enroll in 13-15 credits each semester in the program, their classroom contact time may reach 25 hours per week due to the laboratoryintensive curriculum. The time commitment necessary for success in the MLS program was underestimated by many students. Another issue we encountered was the debatable validity of prerequisite course grades from different institutions. Transfer students' incoming science or cumulative GPA and individual course grades seemed, at times, inconsistent with students' actual ability and didactic preparation. Because of the University's transfer course policies, the program was not able to require University specific courses if a regional partner college course was deemed equivalent. General admission to the University does not require ACT or SAT scores for transfer students; as a result we did not have standardized testing scores to evaluate language competency or analytical skills for almost half of the applicants.

This may have been compounded by an increased number of non-traditional students; those who were returning to school as older adults and those who had taken only one or two courses each semester to complete the prerequisites. During this program expansion phase current applicants were often second career students or individuals with advanced degrees seeking a stable employment option, while others came from an increasingly diverse demographic. Many applicants worked full-time to support themselves and their families which limited their time for studying outside of class. The program also encountered an increase in multilingual students with varying degrees of English language competency as well as an increase in first generation college students. The MLS major had the distinction of being the most ethnically diverse program on campus with approximately $47 \%$ multilingual students, primarily students of color. ${ }^{15}$ Because the vast majority of multilingual applicants were not International students, but instead had permanent U.S. resident status, the program did not have Test of English as a Foreign Language (TOEFL) scores to evaluate language competency. Although equally qualified, these students were disproportionately placed on academic probation or dismissed from the program, perhaps in part due to the competency-based nature and rigor of the program's courses. These students were also primarily transferring into the MLS program from outside the University. Even students who successfully completed the program encountered a number of unexpected personal barriers and/or accessed multiple University level support services such as the Student Success Center, Disability Resources, and/or the Counseling Center.

Students from all backgrounds seemed to bring an ever-increasing number of non-academic issues that were not evident by merely evaluating a GPA for admission or by the brief encounter during an advising appointment. Issues such as understanding the expectations of academic integrity, expectations for personal responsibility, resilience, tolerance for ambiguity, self-management and self-care were impacting our student graduation rates as well as impacting student and employer satisfaction. ${ }^{15}$ Although these may not be directly related to the expansion of enrollment, these factors became far more evident with the increased student numbers and increase in transfer students. In addition, although students read, discussed and signed off on the program's Technical Standards (Essential Functions) as part of the admissions process, many were not able to consistently meet these requirements, especially the behavioral and self-management competencies. ${ }^{16}$ These issues also greatly affected the successful students; i.e. those who did not encounter academic or non-academic difficulties in the program and graduated on-time. Many faculty and program resources were directed toward supporting probationary students and those who were eventually dismissed instead of "equitably" across the entire student cohort. As a result it was necessary to promptly address these issues through strategic planning.

After initial analysis of graduate outcomes and review of the literature, faculty made a number of changes to the prerequisite courses as well as updating scaffolding across the curriculum and within individual courses. Through an extensive curriculum mapping project in 2011 most courses were converted to a hybrid or flipped classroom format applying 
concepts of universal design within the course management system. There are multiple advantages to this hybrid delivery format supporting student success. Students are empowered to select the time and place they wish to study, which in turn supports their task engagement levels. Multilingual speakers or those who want additional content review can repeat the online lecture materials and virtual laboratory activities as many times as they wish. However, even with the curricular changes and overall improved student outcomes, the program still had problematic retention issues, especially for non-traditional students. Faculty began to look for a more holistic admissions process to help ensure that admitted candidates were better prepared for successful completion of the program and for future employment.

\section{The New Selection Model}

The MLS program looked for an equitable mechanism that could be applied to all applicants to assess candidates' background knowledge and skills as well as their language competency with as little subjectivity or bias as possible while maintaining a fair process for all students. Faculty debated the value of letters of reference and personal statements by candidates as part of the application process. But because faculty had only rarely seen a neutral or negative letter of reference and because personal statements may not truly represent the candidate's personal writing ability, the program decided to go a different route. Faculty therefore proposed an interview and a performance assessment method for all candidate competencies derived from the Technical Standards (Essential Functions) required to enter, and continue in the program, as well as the skills and abilities required for employment.

\section{Two Stage Selection Process}

Applicants were evaluated first for whether they met the minimum recommendations for cumulative, science (all science courses), and prerequisite science GPA and completion of science prerequisite courses with a grade of $\mathrm{C}$ or higher. Applicants were then ranked on a weighted scale and the top candidates were invited for the Interview and Skills Test. To minimize the potential impact of inflated prerequisite transfer grades, during the second phase of review candidates were ranked only on points earned on the
Interview and Skills Test; with the highest ranked candidates offered admission. This aligned with literature findings that increased weighting on noncognitive factors increases admissions potential for minority students while maintaining academic quality of applicants. ${ }^{17}$ To assess the efficacy of this new model and selection process, the program performed a retrospective evaluation comparing students who graduated on-time (successful) to those who were delayed due to academic probation and those who failed courses and were eventually dismissed from the program.

\section{MATERIALS AND METHODS}

\section{The Interview}

The faculty developed a formal interview process similar to most admissions practices of medical and allied health education programs. Faculty worked together to focus the Interview toward key items in the Technical Standards related to language ability, ethics, perseverance, personal responsibility, and understanding of the profession. Interview topics were selected from literature and from consultations with other allied health programs at our University. Lengthy faculty discussions followed to identify expected performance ratings on each question, develop a rubric, and to standardize interviewer ratings.

Two faculty members (randomly arranged) interviewed each candidate. Five scenarios or questions were presented to the candidate where they were asked to respond or judge and discuss the situation. The focus of the Interview was to evaluate the candidate's ability to meet the Technical Standards related to communication, stability, affective/valuing, and professional skills. The candidate's answers were evaluated on their ability to express themselves and their reasoning process more than graded for a specific right or wrong answer. The final item concerned the candidate's attitude and general conduct during the Interview. Each item was rated using a simple two or three point rubric scale. A key factor was keeping the focus on the purpose of the question (Technical Standards factor) and the standardized rubric to help minimize personal or cultural bias during ratings. Interviewers rated the applicants' responses individually using the rubric and explanatory comments were strongly encouraged 


\section{EDUCATION}

to support their ratings. These comments were helpful during final discussions or when rater discrepancies occurred.

\section{The Skills Test}

To assess additional items from the Technical Standards, faculty developed a "Skills" Test. Because the laboratory profession is heavily weighted toward performance on demand, the Skills Test included multiple task stations similar to those of a laboratory competency exam. The Skills Test provided objective information about a candidate's language competencies, ability to follow instructions, basic math and science background knowledge, as well as an assessment of visual acuity and fine motor ability. Each station on the Skills Test had brief instructions and a task to be completed. All questions were open ended instead of multiple-choice format, except for the reading comprehension station. The stations were timed but students could move early to the next station if desired. The vast majority of students, including multilingual students, completed the tasks well within the time limits.

The Skills Test included eight stations. The first station, which asked them to write their name on the paper and read the instructions, was not graded or timed. Students were also assessed for arriving ontime and completing the stations in order as directed in the instructions. The measurement task (Fine Motor, Visual Acuity, Cognitive Application) asked students to measure an object's length using a ruler with different scales. To help ensure test integrity, the object and the scales (in, $\mathrm{mm}, \mathrm{cm}$ ) were changed each day of interviews. The math problem (Cognitive Application), which also changed each day, asked students to solve a simple arithmetic order of operations task (add, subtract, multiply, divide). The visual acuity station asked students to count the number of dots within a shape on a card; the shape and background color changed each day. The buffer station (Cognitive Application), asked students to determine the amount of buffer required to make up a solution. This question could have been a complicated one, but instead it actually was a simple ratio problem using the chart provided to make up the volume requested. It did require critical reasoning and problem solving skills.
The next station in the Skills Test used the Purdue Pegboard (PPB) which is a standardized test of bimanual dexterity, evaluating both gross and fine motor skills. ${ }^{18}$ Candidates are seated at a table and after practice were allowed three chances to assemble as many pegs and washers as possible in 30 seconds. The PPB test was developed originally for assembly line worker assessment, but has been used for a number of professional and medical assessments. ${ }^{19}$ The following station used a practice TOEFL paragraph for assessment of reading comprehension ability (Communication, Cognitive Application). Students read a paragraph scenario and responded to six multiple choice questions. The questions required students to interpret the reading passage instead of asking them to find specific information. The TOEFL practice assessment was selected to provide a nonbiased reading passage due to the high percentage of multilingual students in our applicant pool. The final station was an assessment of writing ability (Communication, Cognitive Application). At this station students were provided with a laptop computer which was already opened to a new Notepad document. They were asked to describe an object provided to them using correct spelling, punctuation, and grammar as if they were talking to a friend on the telephone. Note Pad was chosen because it doesn't highlight spelling, grammar, or punctuation errors in the text. The writing passages were rated independently by two faculty using a simple rubric: whether the evaluator could understand the description and the number of technical errors. The time limits for the reading and writing stations were set after consultation with the University's Writing Center faculty who work with multilingual students.

\section{Study Participants}

Students who entered the program during the 2013 and 2014 admissions cycle (graduating classes of 2014 and 2015 respectively) were selected for a retrospective analysis comparing those who remained in good standing throughout the program (on-time graduation) to those placed on academic probation (delayed) and those who were eventually dismissed from the program. Cumulative, overall science, and prerequisite science GPAs were obtained from application files. Because these students had been admitted using the new admissions process, their performance on individual items of the Interview and 


\section{EDUCATION}

Skills Test was evaluated for a possible relationship with student program success (graduation). Total scores on the Board of Certification (BOC) exam were also compared for students who graduated on-time and those who were delayed but eventually graduated to see if any of the admission's factors aligned with this program metric.

\section{RESULTS}

To determine which factors might be associated with student success or failure, two cohorts of students were placed into three groups based on their program completion status: those who successfully graduated on-time (Good Standing $\mathrm{n}=91$ ), those who struggled but eventually graduated (Probation $n=16$ ), and those who did not graduate (Dismissal $\mathrm{n}=14$ ). A preliminary analysis of variance (ANOVA) revealed a violation of Levene's homogeneity of variance for four of the 21 factors involved in the application and review process, necessitating a different approach to data analysis. A t-test analysis was chosen over nonparametric analysis because the t-test provides reliable statistical results when group variances either are or are not equal. Because the primary purpose of an admissions selection process is to differentiate between students who will be successful (graduate ontime) and those who will be delayed or may not be successful, the probation and dismissed students were collapsed into a single group $(n=30)$ to evaluate the admissions factors. An independent samples t-test was then conducted to compare the unweighted admissions process scores for students who graduated on-time and those who were delayed or dismissed.

Among the first phase (cognitive) selection factors, science GPA (sGPA) and prerequisite science GPA (preGPA) differed significantly for good-standing students compared to probation/dismissed students. Cohen's $d$ statistic indicated a large effect size for the science GPA $(d=.831)$ and a moderate effect for the prerequisite science GPA factor $(d=.648)$ suggesting a practical significance for these evaluations. No other first-phase factors were significantly different between the groups (Table 1). An independent samples t-test assessment of Interview items indicated significant differences on knowledge of the MLS profession, discussions of time management strategies, and conflict management (Table 2). Although statistically significant, the MLS knowledge and Time management Interview ratings showed only a minimal effect size. However, the Interview ratings on conflict management showed a moderate effect size $(d=.657)$ suggesting a practical significance for this factor. Several items on the Skills Test showed statistically significant differences when comparing students' eventual success status in the program (Table 2). Student performance on the math problem showed a small to moderate effect size $(d=.369)$ between the groups, while a large effect size was seen for the ruler measurement station $(d=.973)$, chemistry buffer problem $(d=.763)$, writing activity $(d=.800)$ and Purdue Pegboard stations ${ }^{\mathrm{TM}}(d=.1 .150)$.

Table 1. First Phase Admission Factors for MLS Students Graduating On-Time Compared to Delayed/ Dismissed Students ( $\mathrm{n}=121$ )

\begin{tabular}{|c|c|c|c|c|c|c|c|}
\hline \multirow[b]{2}{*}{ Factor } & \multicolumn{2}{|c|}{ Graduated On-Time } & \multicolumn{2}{|c|}{ Delayed/Dismissed } & \multirow[b]{2}{*}{$\mathrm{t}(119)$} & \multirow[b]{2}{*}{$\mathrm{p}$} & \multirow[t]{2}{*}{ Cohen's d } \\
\hline & $\mathrm{M}$ & SD & $\mathrm{M}$ & SD & & & \\
\hline Cum GPA & 3.43 & .30 & 3.33 & .26 & 1.538 & .127 & .356 \\
\hline Sci GPA & 3.33 & .40 & 3.01 & .37 & 2.018 & $.046^{*}$ & .831 \\
\hline Pre GPA & 3.44 & .39 & 3.17 & .44 & 2.179 & $.033^{*}$ & .648 \\
\hline Grades Below C & 8.56 & 3.16 & 9.17 & 3.03 & -.920 & .360 & -.197 \\
\hline Repeat/ Withdraw & 7.06 & 3.67 & 7.13 & 3.20 & -.104 & .917 & -.020 \\
\hline
\end{tabular}


Table 2. Second Phase Admission Factors for MLS Students Graduating On-Time Compared to Delayed/ Dismissed Students $(n=121)$

\begin{tabular}{|c|c|c|c|c|c|c|c|}
\hline \multirow[b]{2}{*}{ Factor } & \multicolumn{2}{|c|}{ Graduated On-Time } & \multicolumn{2}{|c|}{ Delayed/Dismissed } & \multirow[b]{2}{*}{$t(119)$} & \multirow[b]{2}{*}{$p$} & \multirow[t]{2}{*}{ Cohen's $d$} \\
\hline & $M$ & $S D$ & $M$ & $S D$ & & & \\
\hline \multicolumn{8}{|l|}{ Interview } \\
\hline MLS Knowledge & 2.59 & .51 & 2.30 & .61 & 2.660 & $.009^{*}$ & .052 \\
\hline Time Management & 2.62 & .47 & 2.38 & .58 & 2.247 & $.026^{*}$ & .045 \\
\hline Conflict & 2.92 & .37 & 2.35 & 1.17 & 2.643 & $.013^{*}$ & .657 \\
\hline Ethics & 2.88 & .28 & 2.80 & .39 & 1.274 & .205 & .236 \\
\hline Oral Communication & 4.03 & 1.76 & 3.68 & 1.95 & .933 & .353 & .188 \\
\hline Affective/Attitude & 2.89 & .94 & 2.68 & 1.04 & 1.021 & .309 & .212 \\
\hline
\end{tabular}

\begin{tabular}{|c|c|c|c|c|c|c|c|}
\hline Skills Test & & & & & & & \\
\hline Arrived On-Time & .48 & .50 & .45 & .50 & -.155 & .877 & .059 \\
\hline Stations In Order & .12 & .42 & .20 & .76 & -.703 & .483 & -.130 \\
\hline Identify Glassware & .78 & .42 & .77 & .43 & .125 & .901 & .024 \\
\hline Measurement & .39 & .49 & .03 & .18 & 5.782 & $.000^{* *}$ & .973 \\
\hline Math Problem & .83 & .38 & .67 & .48 & 1.962 & $.042^{*}$ & .369 \\
\hline Chemistry Problem & .41 & .49 & .10 & .30 & 4.077 & $.000^{* *}$ & .763 \\
\hline Visual Acuity & .99 & .11 & .87 & .35 & 1.907 & .066 & .463 \\
\hline Reading Comp & 4.33 & 1.05 & 3.25 & 2.50 & 1.360 & .192 & .563 \\
\hline Writing Activity & 3.99 & .92 & 3.07 & 1.34 & 3.485 & $.001^{* *}$ & .800 \\
\hline Purdue Pegboard ${ }^{\mathrm{TM}}$ & 38.44 & 6.33 & 30.83 & 6.89 & 5.578 & $.000^{* *}$ & 1.150 \\
\hline
\end{tabular}

$* p<.05$

$* * p<.01$

Finally, a retrospective analysis was performed to compare scores on the BOC for the 87 students who had taken the exam (on-time $n=78$ vs delayed $n=9$ ). A preliminary analysis was performed to show no violation of homogeneity. An independent t-test showed no significant differences between these two groups' BOC scores $[t(85)=1.510 ; p=.135]$. There was however significant correlation between the student's total score on the BOC exam and their cumulative, overall science and prerequisite science GPA. There

were also significant positive correlations between students' total score on the BOC exam and ratings on several factors of the Interview and Skills test (Table $3)$. The coefficient of determination indicated that $22 \%$ of the BOC exam score variance can be explained or attributed to the student's prerequisite GPA.

\section{DISCUSSION}

The faculty of this MLS Program developed a holistic admissions selection process which addressed some of 
EDUCATION

\begin{tabular}{|c|c|c|c|}
\hline Factor & $\begin{array}{l}\text { Pearson Correlation } \\
\mathrm{r}\end{array}$ & $\begin{array}{l}\text { Sig. (2-tailed) } \\
\text { p }\end{array}$ & $\begin{array}{l}\text { Coefficient of } \\
\text { Determination\# }\end{array}$ \\
\hline Cum GPA & $0.211^{*}$ & .050 & 4.5 \\
\hline Sci GPA & $0.290^{* *}$ & .007 & 8.4 \\
\hline Pre GPA & $0.472^{* *}$ & .002 & 22.3 \\
\hline Grades Below C & 0.042 & .699 & -- \\
\hline Repeats/Withdraws & 0.003 & .980 & -- \\
\hline MLS Knowledge & 0.003 & .980 & -- \\
\hline Time Management & $0.256^{*}$ & .017 & 6.6 \\
\hline Conflict Management & 0.09 & .409 & -- \\
\hline Ethical Discussion & 0.033 & .763 & -- \\
\hline Oral Communication & $0.228^{*}$ & .033 & 5.2 \\
\hline Affective/Attitude & $0.256^{*}$ & .017 & 6.6 \\
\hline Arrive On-Time & 0.178 & .098 & -- \\
\hline Talk/Order & 0.148 & .174 & -- \\
\hline Glassware & 0.012 & .915 & -- \\
\hline Measure & 0.096 & .382 & -- \\
\hline Chemistry/Buffer & $0.336^{* *}$ & .002 & 11.3 \\
\hline Visual Acuity & -0.083 & .445 & -- \\
\hline Reading Comp & -0.041 & .889 & -- \\
\hline Writing & 0.175 & .107 & -- \\
\hline Purdue Peg & 0.121 & .266 & -- \\
\hline
\end{tabular}

** Correlation is significant at the 0.01 level (2-tailed)

* Correlation is significant at the 0.05 level (2-tailed)

\# Percent shared variance

the concerns they faced regarding student retention while providing assessment of the candidates' ability to meet several critical items of the program's Technical Standards. Even though factors such as arriving on-time for the Interview and Skills Test as well as completing the Skills Test stations in order were not significantly different for students who graduated on-time compared to probation/dismissal students, faculty opted to retain these markers for future assessment. Faculty did decide to drop the glassware identification from the Skills Test in part because there were no significant differences between the groups and because it was deemed archaic for current program outcomes. It was evident from this analysis that students who entered the program with a science GPA below 2.90 were at academic risk of probation and/or dismissal from the program. However, after consultation with University administration, the program was only allowed to raise the application GPA to 2.75 for cumulative, prerequisite science and overall science GPA. Faculty agreed that they had occasionally seen students who did poorly in their early college years but improved as they progressed and could be successful in the MLS program, they therefore agreed to set the GPA limit to 2.75. Faculty believed that the second phase of the selection process would provide additional information about the student's possible success in the program for students between 2.90 and 2.75.

As the program implemented this new selection process there has been a slight decrease in ethnic diversity of admitted students from $47 \%$ to $40 \%$, which faculty will continue to monitor. Students' overall attrition rates have decreased to $4 \%$ in the current cohort, along with a decrease in the number 
of students placed on academic probation. Reviews of program retention rates and performance on the admissions factors may help faculty eventually identify reliable cut-off points for each of the second phase admissions items. Faculty may wish to increase the relative weight for factors which were significantly associated with student success in the program for future admission cycles. In an effort to better prepare applicants, recruitment activities have begun to emphasize the important issues associated with success in the program as part of the discussions with interested students. To address this issue, the program developed an online tutorial as well as in-person group advising sessions along with brochures and flyers that also emphasize these critical factors for successful completion of the MLS program. We are also working with recent graduates (on-time and delayed) to develop information for potential and current students about strategies for school, work, and life balance.

\section{LIMITATIONS}

Due to the small number of students in the probation $(\mathrm{n}=16)$ and dismissal $(\mathrm{n}=14)$ groups compared to the on-time graduation group $(\mathrm{n}=91)$, statistical comparison of the groups an ANOVA could not be performed. The Levene's Homogeneity of Variance assumption was violated for four of the 21 admissions factors requiring us to collapse the probation and dismissed students into a single group to perform a ttest or resort to non-parametric analysis. A nonparametric alternative to ANOVA (Kruskal-Wallis) revealed the same factors of significance across the three groups. An alternate t-test analysis was also performed, collapsing the probation status students with the on-time graduation students and comparing them to the dismissed students. With the exception of the Interview question on knowledge of MLS, the same factors were significant using either approach. However faculty determined that the focus of an admissions process should minimize, if not eliminate, students who struggle in the program when possible. Therefore combining the delayed and dismissed students into a single group was the chosen approach. Continuing assessment will be made as the admissions selection process evolves such that minimal limits can eventually be established for several factors and changes in weighting for individual factors may be determined.
Other programs will need to perform studies with their specific prerequisite courses as these effects may differ by school. Our results and those found in the literature indicate that the science or prerequisite science GPA and verbal scores such as those from standardized tests were consistently valid across programs and schools. Specific details about the Interview questions and Skills Test design are available upon request.

\section{REFERENCES}

1. Scott AH, Chase LM, Lefkowitz R, Morton-Rias D, Chambers C, Joe J, et.al. A national survey of admissions criteria and processes in selected allied health professions. J Allied Health, 1995 Spring;24(2):95-107.

2. Elam CL, Seaver DC, Berres PN, Brandt BF. An Overview of Admission Processes for Medical, Dental, Pharmacy, Physical Therapy, and Physician Assistant Programs. NACADA Journal. 2000 Spring;20(1):24-32.

3. Alzahrani MJ, Thomson EM, Bauman DB. Predictors of Student Success in an Entry-Level Baccalaureate Dental Hygiene Program. J Dent Hyg, 2007;81:2.

4. Austin LD. Predicting National Dental Hygiene Board Examination Success Based on Specific Admission Factors. J Dent Hyg. 2011;85(4):335-9.

5. Downey, MC, Collins MA, Browning WD. Predictors of Success in Dental Hygiene Education: A Six-Year Review. J Dent Educ. 2002;66(11):1269-73.

6. Grossbach A, Kuncel NR. The Predictive Validity of Nursing Admission Measures for Performance on the National Council Licensure Examination: A Meta-Analysis. 2011; J Prof Nurs 27: 124-8.

7. Goodyear N, Flampe M. Standardized Test Scores as an Admission Requirement. Clin Lab Sci. 2004;17(1):19-24.

8. Kreiter CD, Kreiter YA Validity Generalization Perspective on the Ability of Undergraduate GPA and the Medical College Admission Test to Predict Important Outcomes. Teach Learn Med 2007;19:2,95-100, DOI: 10.1080/1040 1330701332094

9. Siu E, Reiter HI. Overview: what's worked and what hasn't as a guide towards predictive admissions tool development. Adv in Health Sci Educ. 2009;14:759-75 DOI10.1007/s10459-0099160-8

10. Ingrassia JM. Successful Admission Criteria to Predict Academic and Clinical Success in Entry-Level Radiography Programs. Radiologic Technology. May/June 2016:87(5).

11. Bureau of Labor Statistics, U.S. Department of Labor, Occupational Outlook Handbook, 2016-17 Edition, Medical and Clinical Laboratory Technologists and Technicians, Available at http://www.bls.gov/ooh/healthcare/medical-andclinical-laboratory-technologists-and-technicians.htm Accessed 2016 January.

12. Passiment E. Washington Report: Update on the laboratory workforce-shortage crisis. MLO Med Lab Obs. March 2006:64.

13. Carden R, Allsbrook K Thomas R. An examination of the supply and demand for clinical laboratory professionals in the United States. J Blood Serv Manage. 2009;49;2520-3.

14. Garcia E, Ali AM, Soles RM, Lewis G. The American Society for Clinical Pathology's 2014 Vacancy Survey of Medical 


\section{EDUCATION}

Laboratories in the United States. Am J Clin Pathol 2015;144:432-43. DOI: 10.1309/AJCPN7G0MXMSTXCD

15. MLS Program Annual Report 2010 - 2015. Unpublished internal survey data

16. University of Minnesota Medical Laboratory Sciences Program Technical Standards. Available from: http://cahp.umn.edu/ essential-functions-mls. Accessed 2015 Dec 18.

17. Ballejos MP, Rhyne RL, Parkes J. (2015) Increasing the Relative Weight of Noncognitive Admission Criteria Improves Underrepresented Minority Admission Rates to Medical School,
Teaching and Learning in Medicine. 2015;27(2):155-62, DOI: 10.1080/10401334.2015.1011649

18. Tiffin J and Asher EJ. The Purdue Pegboard: norms and studies of reliability and validity. J App Psych. 1948:32(3);234-47. Available at http://dx.doi.org/10.1037/h0061266 Accessed 2011 October.

19. Causby R, Reed L, Mcdonnell M, Hillier S. Use of Objective Psychomotor Tests in Health Professionals. Percept Mot Skills. 118;765-804. doi: 10.2466/25.27.PMS.118k 27w2 